\title{
Şişen Zeminlerin Kireç Kolonu İle İyileştirilmesinde Kür Süresinin Belirlenmesine Yönelik Bir Yaklaşım
}

\author{
An Approach to Determination of Curing Time in Stabilization of Swelling Soils with Lime \\ Column
}

\author{
Derya TOKSÖZ HOZATLIOĞLU D
}

Sivas Cumhuriyet Üniversitesi, Mühendislik Fakültesi, Jeoloji Mühendisliği Bölümü, Sivas

Geliş (Received): 20 Kasım (November) 2020 / Düzeltme (Revised): 03 Mart (March) 2021 / Kabul (Accepted): 04 Mart (March) 2021

\section{$\ddot{O Z Z}$}

Şişen zeminler jeoteknik açıdan sorunlu zeminler olup bu zeminlerin inşaat öncesi çalışmalarda belirlenmesi ve uygun önlemlerin alınması gerekmektedir. Alınacak önlemler arasında en sık başvurulan yöntem zeminin yerinde yapılan işlemlerle iyileştirilmesidir. En yaygın olarak kullanılan iyileştirme yöntemlerinden biri ise kireç kolonu tekniğidir. Şişen bir zemin kireç kolonu ile iyileştirilmeden önce laboratuvar ortamında kireç kolonunun söz konusu zemin için uygun olup olmadığı araştırılır. Bu ise arazinin küçük ölçekli bir modelinin laboratuvar ortamında oluşturulması ile yapılır. Oluşturulan modeller iyileşmenin sağlanabilmesi için belirli bir kür süresine bırakılır. Uygun kür süresinin belirlenmesi kireç kolonunun performansı için önemlidir. Bu çalışmanın amacı kireç kolonu performansının belirlenmesine yönelik oluşturulan laboratuvar modellerinde kür süresinin kolay ve ekonomik bir yöntemle belirlenebilirliğinin araştırılmasıdır. Söz konusu yöntem, iyon göçü mesafesinin bir asit baz indikatörü olan fenolftalein ile ölçülmesine dayanır. Çalışmanın amacına yönelik olarak bir Na-bentonit kili için laboratuvar ortamında küçük ölçekli bir model hazırlanmıştır. Oluşturulan modelde kireç kolonundan itibaren olan iyon göçü mesafesi değişik kür sürelerinde fenolftalein yardımı ile ölçülmüş ve iyon göçü sabitleşmeye başladığında ölçümlere son verilmiştir. İyon göçünün sabitleşmeye başladığı süre kür süresi olarak alınmıştır. Bu çalışmadan elde edilen sonuçlar kireç kolonunun laboratuvar uygulamalarında kür süresi belirlenirken fenolftaleinin iyi bir araç olabileceğini göstermiş̧ir.

Anahtar Kelimeler: Şişen Zemin, Kireç Kolonu, İyon Göçü, Laboratuvar Modeli, Kür Süresi

\begin{abstract}
Swelling soils which are problematic in terms of geotechnics should be determined in preliminary works and appropriate cautions should be taken. The most frequently used method among the cautions to be taken is to stabilize soil with in-situ operations. One of the most widely used stabilization methods is lime column technique. Before stabilizing a swelling soil with lime column technique, it is investigated if the lime column works for the soil. This is done by creating a small-scale model of the land in the laboratory. The created models are left for a specific curing time to ensure the stabilization. Determination of the appropriate curing time is important for the performance of lime column. The aim of this study is to determine the curing time for the laboratory models, which are designed for investigating lime column performance, with an easy and economic method. The method is based on measuring the ion migration distance by using phenolphthalein which is an acid base indicator. In the scope of the study, a small scale laboratory model was designed for a Na-bentonite clay. The ion migration distance from the lime column in the
\end{abstract}


Toksöz Hozatlıoğlu

model was measured by using phenolphthalein in various curing times and the measurements were stopped when the ion migration distance reached a constant value. The time in which the ion migration distance started not to change was taken as the cure time. The results obtained in this study showed that phenolphthalein can be a useful tool for determination of curing time in the laboratory applications of lime column.

Keywords: Swelling Soil, Lime Column, Ion Migration, Laboratory Model, Curing Time

\section{GİRIŞ̧}

Killi zeminler karmaşık bir yapıya sahip olup, geoteknik mühendisleri için genellikle problem oluşturmaktadırlar. $\mathrm{Bu}$ durum killerin plastisitesi, boşluk suyu basıncına sebep olan düşük geçirimliliği, su içeriğine bağl1 hacim değiştirme özelliği, kimyası ve mineralojisinden kaynaklanmaktadır (Rogers ve Glendining, 1997). Killi zeminlerde uygulamada karşılaşılan en yaygın sorunlardan biri şişme problemidir. Şişen zeminler bünyelerine su aldıklarında şişen ve kuruduklarında büzülen zeminler olarak tanımlanır. $\mathrm{Bu}$ zeminlerin, örneğin sadece Amerika'da binalara, hava alanlarına ve diğer tesislere verdiği zarar yılda yaklaşık 9 milyar dolardır. Bu miktar taşkınların, kasırgaların, depremlerin ve hortumların sebep olduğu hasarın yaklaşık iki katıdır (Jones ve Holtz, 1973; Jones ve Jones, 1987). Şişen zeminlerde zemin hareketlerinin çok yavaş olmasından dolayı hasar uzun süre içinde oluşmaktadır, dolayısıyla sonuçlar depremler ve kasırgalardaki kadar zararl1 olmaz ve yalnızca hasara sebep olurlar. Bununla beraber ekonomik kayıp fazla olup, bu kayıpların önemli bir kısmından sorunun tasarım ve inşaat çalışmalarında tespit edilmesi ve uygun önlemlerin alınmasıla kaçınılabilmektedir (Yılmaz, 2007). Alınacak önlemler arasında, şişen zeminin özelliklerinin daha iyi bir zeminle değiştirilmesi, yapı elemanlarının boyutlarının zeminin özelliklerine uygun olarak seçilmesi ya da zemin özelliklerinin istenilen yönde değiştirilmesi gibi yaklaşımlar sayılabilir. Birinci yol oldukça pahalı olup çok az sayıda uygulama görmüştür. İkinci yolun uygulanmasıyla ilgili örnekler olmakla birlikte bu yöntem de bazen pahalıdır. Bu teknikler içinde en çok kullanılan yöntem zeminin yerinde yapılan işlemlerle sağlamlaştırılmasıdır (Tüdeş, 1996). Şişen zeminler için çeşitli iyileştirme yöntemleri olmasına karşın bunlar arasında en sık başvurulanı kimyasal katkı maddeleri ile yapılan iyileştirmedir. Kimyasal iyileştirmede amaç zemini çeşitli katkı maddeleri ile karıştırarak özelliklerinin amaca uygun hale getirilmesidir. Kimyasal iyileştirmenin uygulandığ 1 projelerde en sık olarak kullanılan katkı maddeleri başta kireç olmak üzere uçucu kül, çimento ve bitümlü malzemelerdir (Van Impe, 1989). Bunlar arasında uluslararası literatürde yaygın olarak kullanılan ve performansı konusunda hemen hemen görüş birliği oluşmuş olan katkı maddesi ise kireçtir.

Kireç ile iyileştirilmiş bir zemin elde etmek için en sık olarak kullanılan iki yöntem vardır; zemin içerisinde kireç kolonları oluşturulur veya kireç arazideki zemin ile karıştırılır. Kireç ile zeminin karıştırılması yöntemi fazla derinlere inilmeden yüzeysel olarak uygulanmakta olup, bu yöntemde zemin kazılarak çıkartılır, belirli oranlarda kireç uygun su içeriğinde karıştırılır ve tekrar yerine serilerek sıkıştırılır. Kolon tekniğinde ise zemin içerisinde yaklaşı $1 \mathrm{k} 0.5 \mathrm{~m}$ çapında, $10 \mathrm{~m}$ derinlikte delikler açılır ve kireç zeminle karıştırılmaksızın deliklere doldurulur (Abiodun ve Nalbantoğlu, 2015). Kolon tekniğinin iyileştirme mekanizması kirecin kolonu çevreleyen zemine zamanla difüzyonu sonucu kil ile kireç arasında oluşan fizikokimyasal reaksiyonlara dayanır. $\mathrm{Bu}$ reaksiyonlar kirecin içerdiği pozitif iki değerlikli iyonlar ve negatif 
olarak yüklü kil mineralleri arasında meydana gelir ve iyileştirme mekanizmasının temelini oluşturur. Killi zemin ile kireç arasında ilk olarak kilin kirece olan kimyasal afinitesinden dolay1 katyon değişimi reaksiyonu meydana gelir. Kil minerallerinin katmanları arası kalsiyumla doyurulduktan sonra puzzolonik reaksiyonlar oluşmaya başlar (Bell, 1996). Kirecin içerdiği iyonların kolonu çevreleyen zemine olan göçü bu reaksiyonların ve dolayısıyla iyileşmenin oluşabilmesi için en önemli süreçtir. İyon göçünün oluşabilmesi için ise zamana ihtiyaç vardır. Bu yüzden kireç kolonu uygulamalarında kür süresi kolon performansı için önemli bir faktördür.

Sorunlu bir zemin kireç kolonu tekniği ile iyileştirilmeden önce laboratuvar ortamında arazinin modeli oluşturularak kireç kolonunun söz konusu zemin için performansı araştırılır. Oluşturulan modeller belirli bir kür süresine bırakılır. Genel olarak kür süresi arttıkça kolon performansı da artmaktadır. Kireç kolonu tekniği ile ilgili olarak yapılan önceki araştırmalar kür süresinin 28 gün ve 2 yıl arasında olması gerektiğini önermişlerdir (Ruenkrairergsa ve Pimsarn, 1982; Rogers ve Bruce, 1991; Rogers ve Glendinning, 1997). Ancak bu iki süre arasında oldukça büyük bir fark vardır ve kür süresinin belirlenmesi için genellikle ek bir çalışmaya gerek duyulmaktadır. Kireç kolonu uygulamalarında kür süresi belirlenirken genellikle laboratuvarda aynı özelliklere sahip birden fazla arazi modeli oluşturulur ve bu modeller değişik kür sürelerine bırakılır. Kür süreleri sonunda kireç kolonlarından belirli mesafelerde alınan örnekler üzerinde serbest basınç dayanımı veya serbest şişme deneyleri uygulanarak en iyi iyileştirmenin ve en uzun mesafede göçün hangi kür süresinde olduğuna karar verilir. Ancak iyon göçü mesafesini belirlemek amacıyla yapılan deneyler, özellikle serbest şişme deneyi, zaman ve maliyet gerektiren deneylerdir. Bu çalışmanın amacı kireç kolonu performansını belirlemeye yönelik oluşturulan laboratuvar modellerinde kür süresinin daha kolay ve ekonomik bir yöntemle belirlenebilirliğini araştırmaktır. Söz konusu yöntem iyon göçü mesafesinin bir asit baz indikatörü olan fenolftalein ile ölçülmesine dayanır. Fenolftalein toz halinde beyaz renkli bir bileşik olup asitli ve nötral ortamda renksiz iken bazik ortamda pembe renklidir. Kireç içerdiği hidroksil iyonlarından dolayı yüksek oranda alkalin (bazik) özellik göstermektedir (Glendinning ve Rogers, 1996; Tonoz vd., 2003). Dolayisiyla fenolftalein ile temas halinde pembe bir renk almaktadır. Fenolftalein daha önce kireç kolonu ile ilgili olarak yapılan birkaç çalışmada iyon göçü mesafesini belirlemek için kullanılmıştır. Örneğin, Rogers ve Glendinning (1994), nem içeriğindeki artışın iyon göçü üzerindeki etkisini araştırmak için fenolftalein ile karıştırılmış killeri farklı nem içeriklerinde olmak üzere $32 \mathrm{~mm}$ çapındaki perpeks tüplere doldurmuşlardır. Her tüpün merkezine $6 \mathrm{~mm}$ çapında sönmemiş kireç kolonu oluşturulmuş ve kirecin renk değişiminden faydalanarak iyonların tüpün ucuna ulaşması için gereken zaman ölçülmüş ve kaydedilmiştir. Çalışma sonucunda, nem içeriğindeki artışın iyon göçünü artırdığı sonucuna varılmıştır. Toksöz ve Yılmaz (2020) ise yaptıkları çalışmada şişen kil oranının iyon göçü üzerindeki etkisini araştırmak için değişik oranlarda Na-bentonit içeren zeminleri fenolftalein ile karıştırarak $152 \mathrm{~mm}$ çapındaki kompaksiyon kalıplarına sıkıştırmış ve tüplerin merkezinde $20 \mathrm{~mm}$ çapında kireç kolonları oluşturmuşlardır. Belirli bir küresi sonunda kolonlardan itibaren oluşan renk değişimlerini gözlemleyerek iyon göçü mesafelerini saptamışlardır. Dolayısıyla değişik amaçlara yönelik olarak iyon göçü mesafesi belirlenirken fenolftalein oldukça pratik bir çözüm olarak 
Toksöz Hozatlıoğlu

karşımıza çıkmaktadır. Mevcut çalışmada iyon göçünü fenolftalein ile belirlemedeki amaç ise laboratuvar ortamında yapılan kireç kolonu uygulamalarında kür süresine karar verebilmektir. Çalışmanın amacı kapsamında laboratuvar ölçeğinde bir arazi modeli oluşturulmuş, bu model üzerinden ölçümler alınarak yorumlanmış, elde edilen bulgular ise çalışmanın sonunda sunulmuştur.

\section{MATERYAL VE METOT}

Çalışmanın amacı doğrultusunda ilk olarak laboratuvar modelinde kullanılacak zeminin özellikleri belirlenmiştir. Kullanılan zemin, önemli miktarda Na-montmorillonit içeren bir bentonit olup oldukça yüksek bir şişme potansiyeline sahiptir. Zeminin özellikleri belirlendikten sonra, kür süresini belirlemek amacıyla bir adet küçük ölçekli laboratuvar modeli oluşturulmuştur. Zeminde oluşan iyon göçü mesafesi fenolftalein yardımıyla her haftanın sonunda ölçülmüş ve ölçümler iyon göçü mesafesi sabitleşinceye kadar sürdürülmüştür. İyon göçünün sabitleşmeye başladığı süre ise kür süresi olarak alınmıştır.

\section{Bentonit ve Kirecin Özellikleri}

Araştırma kapsamında kullanılan bentonit Reşadiye (Tokat)' de bulunan ve Samaş A.Ş. tarafından işletilen kil yataklarından elde edilmiştir. Kireç ise sönmüş kireç olup Niksar (Tokat)' da bulunan bir kireç ocağından alınmıştır. Söz konusu bentonit Toksöz ve Yılmaz (2020) tarafından yürütülen bir çalışmada kullanılan bentonit ile aynıdır. Dolayısıyla bentonitin özellikleri söz konusu çalışmadan alınmıştır (Çizelge 1). XRD tüm kayaç çekim ve kil çekim difraktogramları Şekil 1' de sunulmuştur. XRD tüm kayaç çekim difraktogramı incelendiğinde bentonitte mevcut olan minerallerin kil, kuvars, kalsit ve feldispat olduğu görülmektedir. Karakteristik XRD kil çekim difraktogramından görüldügü üzere bentonitin ortalama yarı niceliksel Na-Smektit içeriği \%89 olarak bulunmuştur. Bentonitin diğer fiziksel özellikleri Çizelge 1' de verilmiştir. Kullanılan bentonit oldukça yüksek bir şişme potansiyeline sahip olup Birleştirilmiş Zemin Sınıflama Sistemine (USCS) göre $\mathrm{CH}$ olarak sinıflandirılmaktadır. Ayrica Skempton (1953) tarafından önerilen sınıflamaya göre aktif kil sınıfına düşmektedir (Toksöz ve Y1lmaz, 2020).

Çizelge 1. Kullanılan bentonitin özellikleri (Toksöz ve Yilmaz, 2020).

Table 1. The properties of the used bentonite (Toksöz ve Yilmaz, 2020).

\begin{tabular}{lc}
\hline Özellik & Değer \\
\hline Likit limit (\%) & 269 \\
Plastik limit (\%) & 34.72 \\
Plastisite indeksi (\%) & 234.28 \\
Zemin sınıfı (USCS) & $\mathrm{CH}$ \\
Kil yüzdesi (\%) & 100 \\
Aktivite & 2.34 \\
Maksimum kuru birim & \\
hacim ağırlık (kN/m $\left./ \mathrm{m}^{3}\right)$ & 10.98 \\
Optimum su içeriği (\%) & 42 \\
\hline
\end{tabular}

\section{Laboratuvar Modelinin Oluşturulması}

Kireç içerisindeki iyonların kolondan zemin içerisine olan göç mesafesini ölçebilmek için bir asit baz indikatörü olan fenolftalein kullanılmıştır. Daha önce de belirtildiği gibi, asitli ve nötral ortamda renksiz olan fenolftalein bazik ortamda pembe renge döner. İçerdiği hidroksil iyonları kirece yüksek oranda alkalin (bazik) özellik kazandırmakta (Glendinning ve Rogers, 1996; Tonoz vd., 2003) ve bu ise fenoftalein ile temas etmesi durumunda kirecin pembe bir renk almasına neden olmaktadır (Rogers ve Glendinning, 1994). 


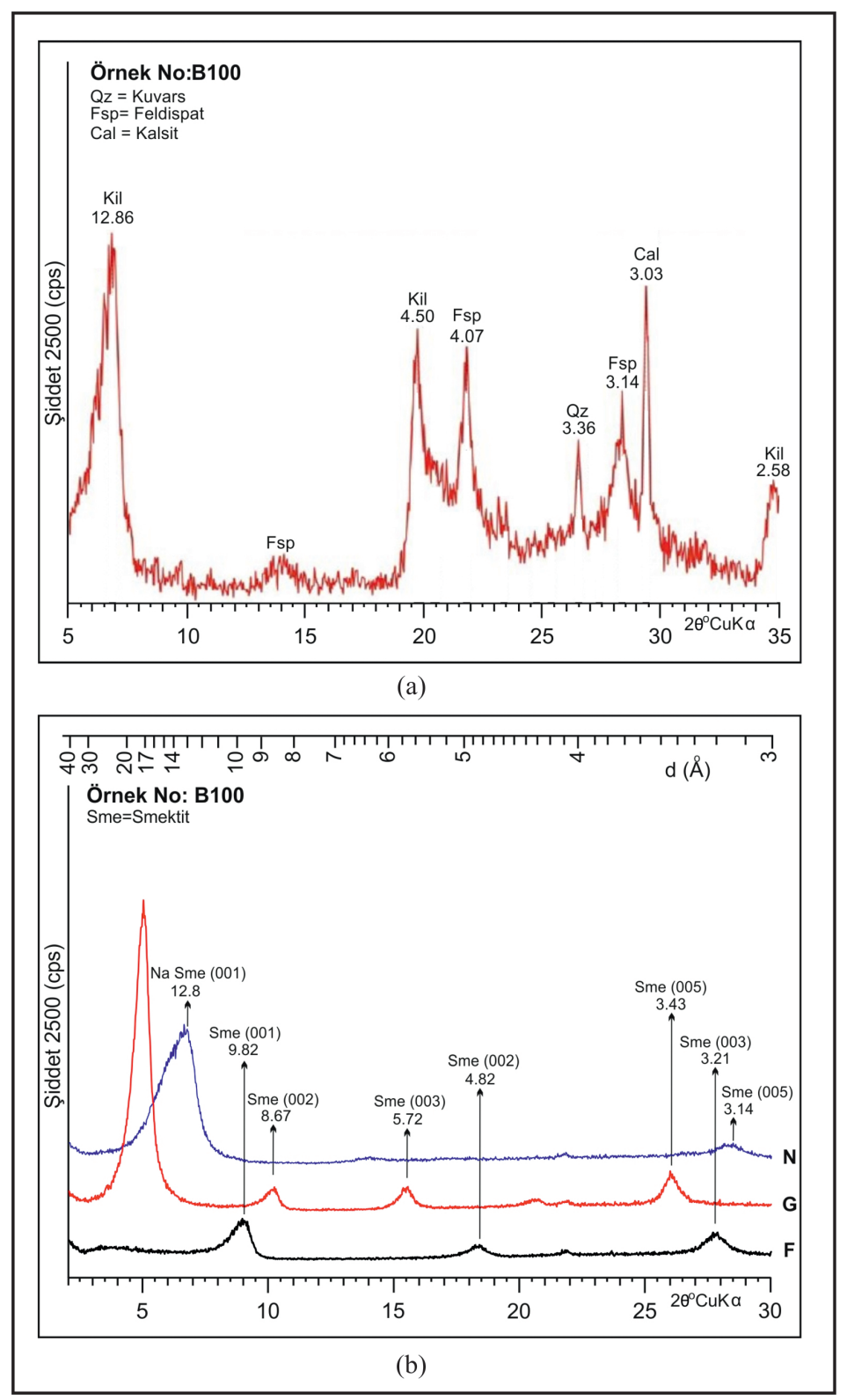

Şekil 1. Bentonite ait XRD difraktogramları: (a) Tüm kayaç; (b) Kil çekim (Toksöz ve Yılmaz, 2020).

Figure 1. XRD diffractograms of bentonite. (a) a bulk (whole) sample; (b) clay fraction (Toksöz and Y1lmaz, 2020).

Fenolftalein ile iyon göçünü belirleyebilmek için öncelikle fenolftalein çözeltisi hazırlanmalıdır. Fenolftalein çözeltisini hazırlamak için $1 \mathrm{gr}$ fenolftalein $50 \mathrm{ml}$ etil alkolde çözülür ve hacim 100 ml'ye tamamlanacak şekilde etil alkol ilave edilir. Eğer bir çökelti oluşursa süzgeç kâğıdı yardımıyla süzülür (Dölen, 2002).

Laboratuvar modelini oluşturmak için öncelikle zemin örneği optimum su içeriğinde ve bir miktar $(50 \mathrm{ml})$ fenolftalein çözeltisi ile 
Toksöz Hozatlıoğlu

karıştırılmıştır. Zemin örneği $152 \mathrm{~mm}$ çapında $115 \mathrm{~mm}$ yüksekliğindeki bir kompaksiyon kalıbına optimum su içeriğinde ve kompaksiyon çekici kullanılarak standart sıkıştırma enerjisinde sıkıştırılmıştır. Ardından bir örnek çıkarıcı kullanılarak tüpün merkezinde $10 \mathrm{~mm}$ çapında bir delik açılmış ve açılan delik sönmüş kireç ile doldurulmuştur. Kireç kolonu oluşturulduktan sonra, modelin üstüne arada filtre kâğıdı olacak şekilde delikli bir plaka yerleştirilmiştir. Ardından iyon göçüne yardım etmesi amacıyla modelin üst tarafından su girişi sağlanmıştır. Oluşturulan modelin kesiti Şekil 2' de verilmiştir.

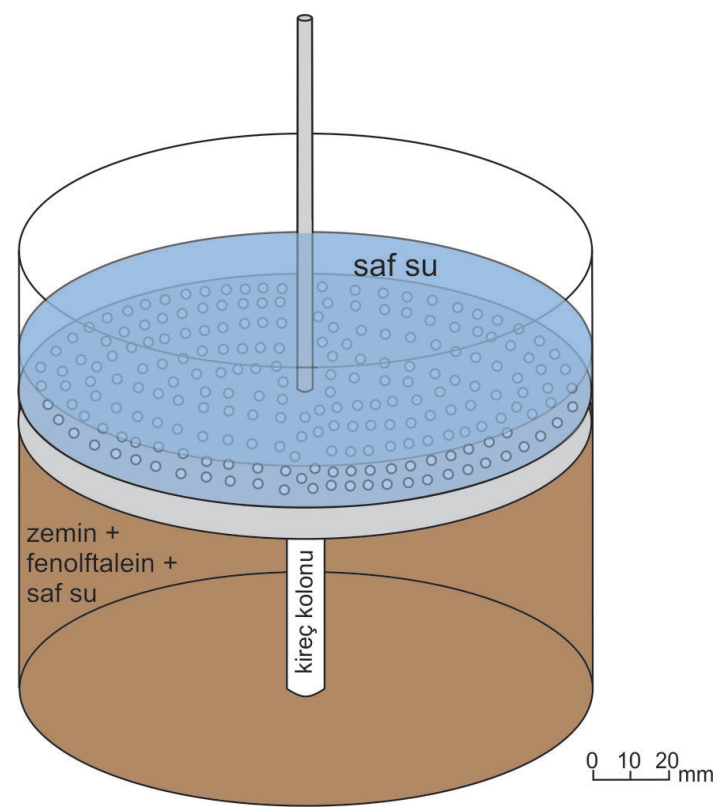

Şekil 2. Oluşturulan modelin kesiti.

Figure 2. Cross section of the created model.

\section{BULGULAR}

Oluşturulan model küre bırakılmıştır. Geçen süre içerisinde, her haftanın sonunda modeldeki su boşaltılıp, demir plaka ve filtre kâğıdı kaldırılıp kolondan itibaren olan göç mesafesi ölçülmüş ve fotoğraflanmıştır. Demir plaka kaldırıldığında kireç kolonu etrafında pembe renkli radyal bir zonun varlığı gözlenmiştir. $\mathrm{Bu}$ renk zemin içerisindeki fenolftaleinin kireç ile temas etmesi sonucu oluşmuştur. Bu renkli zonun sınırları milimetre ölçeğinde ölçülerek kaydedilmiştir. Mesafe ölçümleri kolonun dış kenarından itibaren alınmıştır. $\mathrm{Bu}$ işlemler iyon göçü mesafesi sabitleşinceye kadar sürdürülmüştür. 6. haftadan itibaren iyon göçü mesafesinin değişmediği görülmüş ve 8 . haftada ölçüm alımı sonlandırılmıştır. Örnek oluşturması amaciyla Şekil 3'te 4. haftada alınan mesafe ölçümü gösterilmiştir. Diğer haftalar için ölçülen göç mesafeleri Şekil 4, iyon göçü mesafesinin zamana bağlı olarak değişimi ise Şekil 5'te sunulmuştur. Şekil 4 ve 5 ' te görüldüğü üzere kolondan itibaren olan iyon göçü mesafesi 6 . haftaya kadar artmış ancak bu haftadan sonra sabitleşmiştir. Dolayısıyla aynı zemin için oluşturulacak daha büyük ölçekli laboratuvar modellerinde 6 haftalık bir kür süresi dikkate alınabilir. Maksimum iyon göçü mesafesi ise 12 mm olarak ölçülmüştür. Diğer bir ifadeyle, kolon çapının 1.2 katı kadar bir iyileştirme mesafesi elde edilmiştir. 


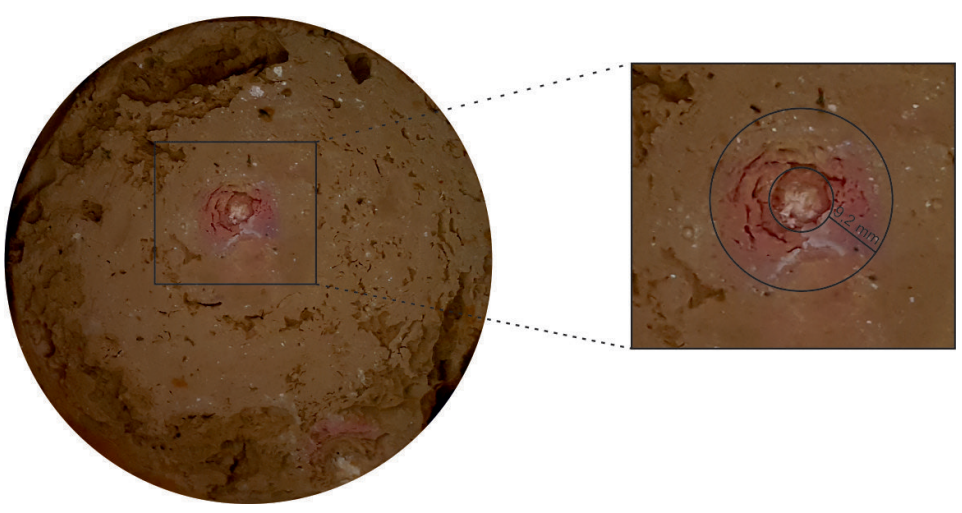

Şekil 3. 4. haftanın sonunda gözlenen iyon göçü mesafesi.

Figure 3. Ion migration distance observed at the end of the 4th week.

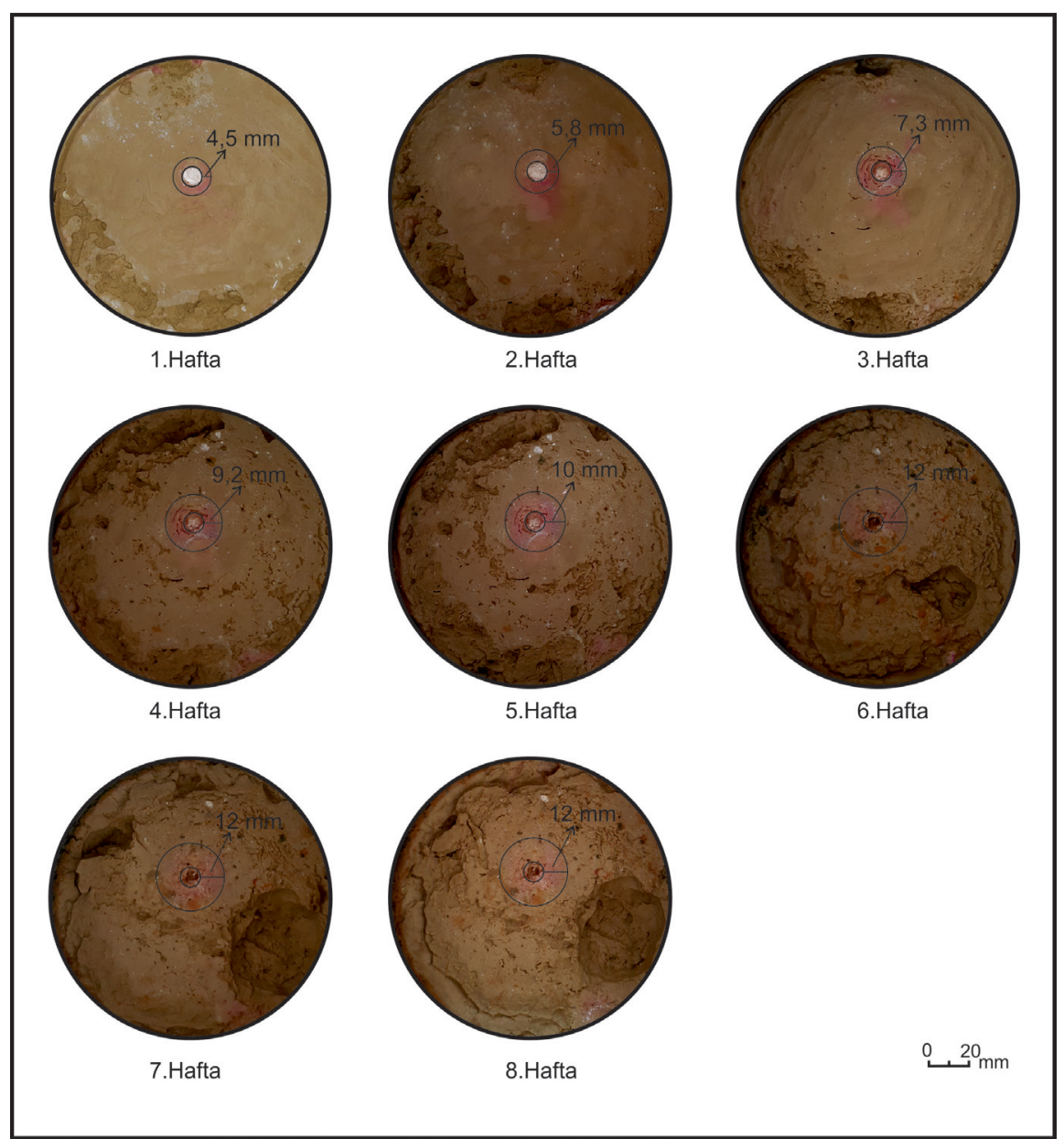

Şekil 4. Kür süreleri boyunca gözlenen iyon göçü mesafeleri.

Figure 4. Ion migration distances during curing times. 
Toksöz Hozatlıoğlu

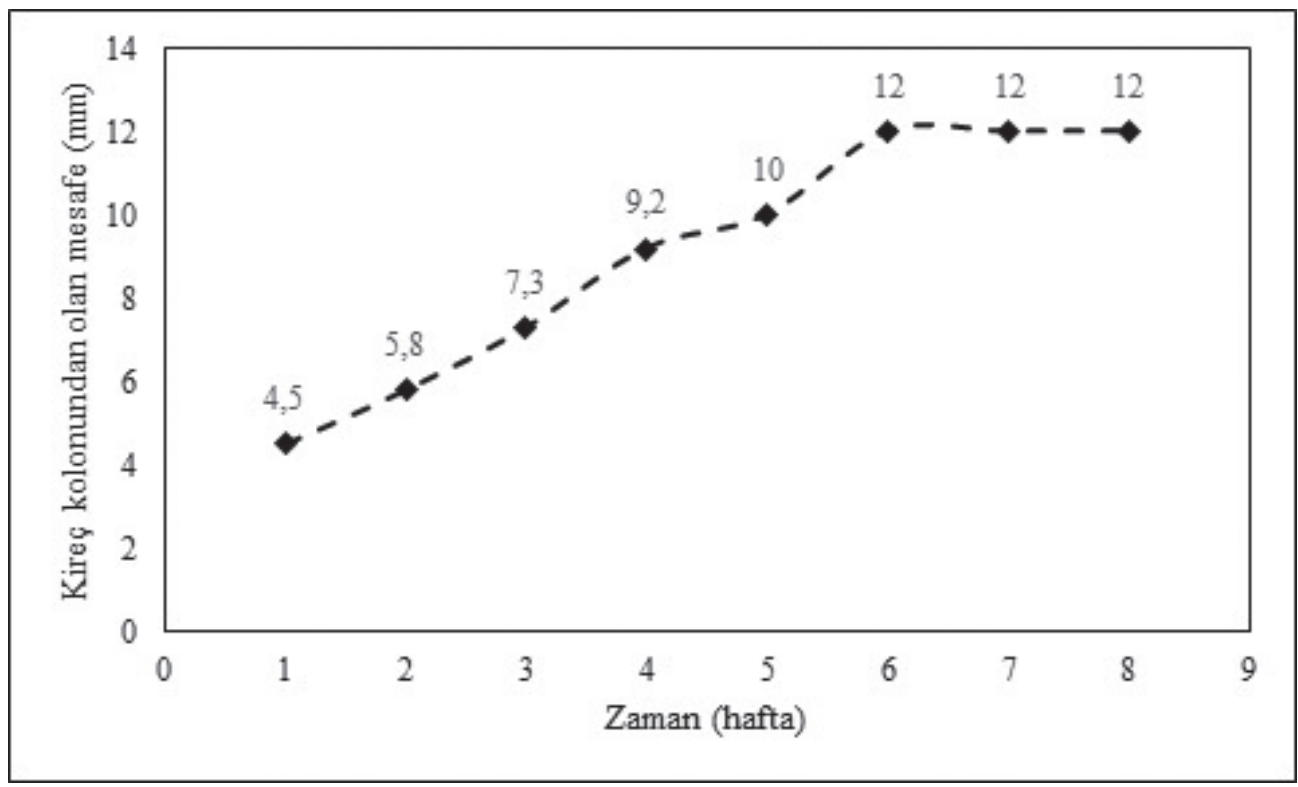

Şekil 5. İyon göçü mesafesinin zamana bağlı olarak değişimi.

Figure 5. Variation of ion migration distance with time.

Elde edilen bulgular konu ile ilgili yapılan daha önceki çalışmaların sonuçlarıyla yaklaşık olarak uyumludur. Toksöz ve Y1lmaz (2020) şişen kil oranının iyon göçü üzerindeki etkisini araştırırken fenolftaleinden faydalanmışlar ve $\% 100$ bentonit içeren zeminde kolon çapının 1.5 katı kadar bir mesafede iyon göçü saptamışlardır. $\mathrm{Bu}$ mesafe mevcut çalışmada elde edilen iyon göçü mesafesinden 1.25 kat daha büyüktür. Ancak bu farklılık iki çalışmada yapılan sulama tekniklerinin farklı olmasından kaynaklanıyor olabilir. Toksöz ve Yılmaz (2020) hazırladıkları modellere kireç kolonundan su vermişlerdir. Oysa mevcut çalışmada modelin üst kısmından su verilmiştir. Suyun kireç kolonundan verilmesi iyon göçünü hidrolik iletkenlikten dolayı arttıracaktır. Toksöz ve Yılmaz (2019b) yapmış oldukları başka bir çalışmada kireç kolonunun Na-bentonit kilini iyileştirmedeki performansını araştırmışlardır. Çalışmada kullanılan bentonit mevcut çalışmada kullanılan bentonit ile aynı özelliklere sahiptir. Araştırmacılar bentoniti 20x30×45 cm boyutunda metal bir kasaya $15 \mathrm{~cm}$ yüksekliğinde olacak şekilde standart kompaksiyon enerjisinde sıkıştırmışlar ve kasanın köşesine $5 \mathrm{~cm}$ çapında bir kireç kolonu oluşturmuşlardır. 2 aylık bir kür süresi sonunda kolondan itibaren belirli mesafelerde alınan örnekler üzerinde serbest şişme deneyi yapmışlar ve kolonun 1 katı kadar bir mesafede iyileşme gözlemlemişlerdir. Bu mesafe bu çalışmada fenolftalein kullanılarak elde edilen iyon göçü mesafesi ile yaklaşık olarak aynıdır. Dolayısıyla fenolftalein ile elde edilen iyon göçü mesafesinin klasik yöntemlerle elde edilen iyon göçü mesafesini yaklaşık olarak yansıttığı söylenebilir. Ayrıca daha büyük ölçekli modellerde yaklaşık eşit miktarda iyon göçü mesafesinin saptanması ölçek etsisinin ihmal edilebilir olduğunu göstermektedir. 


\section{SONUÇLAR VE TARTIŞMA}

$\mathrm{Bu}$ çalışmada kireç kolonu tekniğinin şişen zeminleri iyileştirmedeki performansını belirlemeye yönelik oluşturulan laboratuvar modellerinde kür süresinin daha kolay ve ekonomik bir yöntemle belirlenebilirliği araştırılmıştır. Söz konusu yöntem kireç göçünün zeminde oluşturduğu renk değişiminin sınırlarının ölçülmesine dayanmaktadır. Bu renk değişimi zemin içerisine katılan bir asit baz indikatörü olan fenolftalein ile sağlanmıştır. Çalışmanın amac1 doğrultusunda laboratuvar ortamında bir model çalışması gerçekleştirilmiştir. Belirli bir süre sonra, modeldeki kireç kolonu etrafinda pembe renkli radyal bir zonun oluştuğu gözlenmiştir. $\mathrm{Bu}$ zonun radyal şeklinde olması, renk değişiminin kirecin zemin içerisine olan göçünden kaynaklandığını göstermektedir. Düzenli aralıklarla iyon göçü mesafesindeki değişimler ölçülmüş, iyon göçü mesafesi sabitleştikten bir süre sonra ise ölçümlere son verilmiştir. Elde edilen ölçümler incelendiğinde iyon göçünün ilk 6 haftaya kadar arttığı, bu haftadan sonra ise sabitleştiği görülmüştür. Maksimum iyon göçü mesafesi ise $12 \mathrm{~mm}$ olarak ölçülmüştür. Bu durum bu zemin için elde edilen iyileştirme mesafesinin kolon çapının 1.2 katı kadar olduğunu göstermektedir. Dolayısıyla laboratuvarda oluşturulacak daha büyük ölçekli modellerde kolonlar arasındaki mesafe kolon çapının 1.2 katı kadar ve kür süresi ise 6 hafta olarak seçilebilir.

$\mathrm{Bu}$ çalışmada önerilen yaklaşım ile kireç kolonu uygulamalarında kür süresi birden fazla laboratuvar modeli oluşturmaksızın belirlenebilecektir. Ayrıca birden fazla kireç kolonu içeren laboratuvar modellerinin oluşturulması gerektiği durumlarda, araştırmacılar kolonlar arasında bırakılacak mesafeye zor ve karmaşık laboratuvar deneylerine gerek kalmaksızın karar verebileceklerdir. Elbette ki zeminde oluşan iyileşmenin miktarını belirleyebilmek için serbest şişme ya da serbest basınç gibi deneylerin yapılması gerekmektedir. $\mathrm{Bu}$ çalışmada önerilen yaklaşım bir ön laboratuvar çalışması yöntemi olarak kabul edilip sadece iyon göçü mesafesi ve kür süresine karar vermek için kullanılmalıdır. $\mathrm{Bu}$ yöntem ile elde edilen kür süresi dikkate alınarak oluşturulan daha büyük ölçekli bir modelde kireç kolonu tekniğinin iyileştirme performansı şişme ve dayanım deneyleri ile belirlenmelidir.

\section{KAYNAKLAR}

Abiodun, A.A., Nalbantoglu, Z., 2015. Lime pile techniques for the improvement of clay soils. Canadian Geotechnical Journal, 52 (6), 760-768.

Bell, F.G., 1996. Lime stabilization of clay minerals and soils. Engineering Geology, 42, 223-237.

Dölen, E., 2002. Analitik Kimyaya Giriş Sulu Çözeltilerde Denge. Marmara Üniversitesi, Eczacilık Fakültesi Yayınları, İstanbul.

Glendinning, S., Rogers, C.D.F., 1996. Deep Stabilisation Using Lime, In: Rogers, C.D.F., Glendinning, S and Dixon, N. (Editors). Lime Stabilisation: Proceedings Seminar on Lime Stabilisation, Loughborough University, Thomas Telford, London, pp. 127-138.

Jones, D.E., Holtz, W.G., 1973. Expansive soils - the hidden disaster. ASCE, Civil Engineering, 43, 87-89.

Jones, D.E., Jones, K.A., 1987. Treating expansive soils. Civil Engineering, 57 (8), 62-65.

Reunkrairergsa, T., Pimsarn, T., 1982. Deep hole lime stabilisation for unstable clay shale embankment. Proceedings of the 7th SE Asia Geotechnics Conference, Hong Kong, 631-645.

Rogers, C.D.F., Bruce, C.J., 1991. Slope Stability Engineering. Thomas Telford, London, p 443.

Rogers, C.D.F., Glendining, S., 1994. Deep Slope Stabilisation Using Lime. Transportation 
Toksöz Hozatlıoğlu

Research Record 1440, Transportation Research Board, National Research Council, Washington D.C., USA, 63-70.

Rogers, C.D.F., Glendining, S., 1997. Improvement of clay soils in situ using lime piles in the UK. Engineering Geology, 47, 243-257.

Skempton, A.W., 1953. The colloidal activity of clays. In: Proceedings of the third international conference on soil mechanics and foundation engineering. Zurich, Switzerland, ICOSOMEF, pp 57-61.

Toksoz, D., Y1lmaz, I., 2019a. Influence of swelling clay content on ion migration and column performance in lime column treated soils. Geotechnical and Geological Engineering, 38(1), 813-832.

Toksoz D., Y1lmaz, I., 2019b. A study on the performance of lime column technique for treatment of a Na-bentonite clay. IOP Conference Series: Earth and Environmental Science, 221 (012018).
Tonoz, M.C., Gökçeoğlu, C., Ulusay, R., 2003. A laboratory - scale experimental investigation on the performance of lime columns in expensive Ankara (Turkey) Clay. Bulletin of the Engineering Geology and the Environment, 62, $91-106$.

Tüdeş, E., 1996. Zeminlerin Kireç ve Çimento Katkısı ile Stabilizasyonu. Yüksek Lisans Tezi, Karadeniz Teknik Üniversitesi, Fen Bilimleri Enstitüsü, Trabzon.

Van Impe, W.F., 1989. Soil Improvement Techniques and Their Evolution. A.A. Balkema Rotterdam Brookfield.

Yılmaz, I., 2007. Mühendislik Jeolojisi - İlkeler ve Temel Kavramlar, Teknik Yayınevi, Ankara. 